\title{
SOCIO-DEMOGRAPHIC CHARACTERISTICS AND PSYCHIATRIC COMORBIDITY IN PATIENTS WITH OBSESSIVE-COMPULSIVE DISORDER
}

\author{
Sreekumar Girish Menon'1, Manjunath Rajashekharaiah ${ }^{2}$ \\ ${ }^{1}$ Assistant Professor, Department of Psychiatry, Jubilee Mission Medical College and Research Institute, Thrissur, Kerala. \\ 2Junior Resident, Department of Psychiatry, Shimoga Institute of Medical Sciences, Shimoga.
}

\begin{tabular}{l}
\hline ABSTRACT \\
\hline BACKGROUND \\
Obsessive-compulsive Disorder (OCD) is a distressing anxiety disorder with prevalence of 0.6\% in India. About half of the patients \\
have onset in childhood and adolescence with males having earlier onset. Early onset and male cases have severe illness and poor \\
prognosis. Most of them are unmarried and from middle or upper classes. Patients with poor insight and resistance and comorbidity \\
especially psychosis generally had poor prognosis.
\end{tabular}

\section{MATERIALS AND METHODS}

Socio-demographic data of 50 consecutive patients with OCD diagnosed with ICD-10 criteria were collected and assessed on YBOCS and M.I.N.I.

\section{RESULTS}

$46 \%$ patients were between the age group of $18-25$ yrs., $56 \%$ were female, $62 \%$ were married, $60 \%$ were from rural background, $44 \%$ were educated up to secondary school, $62 \%$ were from middle income group, $70 \%$ had illness of more than $2 \mathrm{yrs}$. and $42 \%$ had depression.

\section{CONCLUSION}

This study showed higher preponderance in females, rural patients, low and middle income group. Most common family history of psychiatric illness was affective disorder and depression was the most common comorbidity.

\section{KEYWORDS}

Obsessive-Compulsive Disorder, Comorbidity, Depression, Awareness.

HOW TO CITE THIS ARTICLE: Menon SG, Rajashekharaiah M. Socio-demographic characteristics and psychiatric comorbidity in patients with obsessive-compulsive disorder. J. Evolution Med. Dent. Sci. 2016;5(55):3727-3732, DOI: 10.14260/jemds/2016/854

\section{INTRODUCTION}

Obsessive-Compulsive Disorder (OCD) is the fourth most common mental disorder characterized by presence of two distinct phenomena: obsessions and compulsions. Patients of OCD find that obsessions and compulsive behaviours are irrational, but cannot suppress them. Prevalence rates of OCD in the range of 2 to 3 percent and is almost equally common in males and females. Prevalence in India is lower $(0.6 \%){ }^{1}$ According to ICD-10, 1992 (International classification of diseases) for a definite diagnosis of OCD, obsessional symptoms, or compulsive acts or both must be present on most days for at least 2 successive weeks and be a source of distress or interference with activities. ${ }^{2}$

This study would try to look whether there is any changing trend with respect to comorbidity and demographic variables in OCD over the years.

\section{MATERIALS AND METHODS/Aims of this Study were}

1. To study socio-demographic variables of patients with OCD.

Financial or Other, Competing Interest: None

Submission 05-06-2016, Peer Review 29-06-2016,

Acceptance 05-07-2016, Published 08-07-2016.

Corresponding Author:

Dr. Manjunath Rajashekharaiah,

\#404, Staff Quarters,

District MCGANN Hospital Compound,

Sims,

Shimoga-577201.

E-mail:docmatic@gmail.com

DOI: $10.14260 /$ jemds/2016/854
2. To study various comorbid psychiatric conditions occurring with OCD.

The study was conducted at the Outpatient Department of Vijayawada Institute of Mental Health and Neurosciences (VIMHANS), Vijayawada. The study population included all the patients visiting the outpatient department from January 2011 to January 2012. A total of 50 patients consecutively diagnosed as obsessive-compulsive disorder as per ICD-10 were taken in this study.

\section{Inclusion Criteria}

1. All cases diagnosed as per ICD-10 diagnostic guidelines for OCD.

2. Patients of the age group 18 to 65 years.

3. Patient agrees to participate in the study by providing written informed consent.

\section{Exclusion Criteria}

1. Patients with severe organic involvement of central nervous system or serious physical illness.

2. Uncooperative and agitated patients.

3. Patients having active substance abuse or intoxicated patients.

\section{Tools for Assessment}

1. Data Sheet: This included information regarding name, age, and sex; marital status, religion, education, and residence; family income, past history, family history, personal history, premorbid personality, current functional status, physical examination, differential 
diagnosis, and final diagnosis.

2. Statistical Analysis: Data was analysed using Statistical Package for Social Sciences (SPSS 16).

3. The Y-BOcS Checklist: The Yale-Brown ObsessiveCompulsive Scale is regarded as the "Gold standard" in the measurement of Obsessive-Compulsive Disorder (OCD) symptom severity and treatment response. 3 The checklist was used in the study with some modifications to suit the requirements of study population.

4. M.I.N.I. Version 5.0: was used for the diagnosis of Axis I disorders. ${ }^{4}$

\section{REVIEW OF LITERATURE}

For centuries in Europe, satanic possession was believed to be the primary cause of obsessive thoughts, which could lead to compulsive behaviours and treatment involved the exorcism. Since fourth century BC, obsessional behaviour was explained as "Melancholia" caused by an imbalance between four bodily fluids or humours. Jean Esquirol first described OCD in psychiatric literature in 1888. The term obsession was coined by Morel in 1866. Formal definition of obsession was first given by Westphal in 1877 as "Thoughts which came to the foreground of consciousness in spite of and contrary to the will of the patient and which he is unable to suppress, although he recognises them as abnormal and not characteristic of himself."

By $20^{\text {th }}$ century, theories of obsessive-compulsive neurosis shifted towards psychological explanation. It was conceptualised as resulting from unconscious conflicts and from isolation of thoughts and behaviours from the emotional antecedents. Freud conceptualised that OCD occurred as a result from fixation at the anal level of psychosexual development.

For many years only one follow up study of a group of patients' reasonable size was published. ${ }^{5}$ Since 1950 , however, a number of very competent studies have appeared, including follow up information. ${ }^{6,7,8}$ There have been some good reviews of this material.9,10

\section{Incidence and Prevalence}

Estimated prevalence in various studies ranges from 0.4$2.5 \%{ }^{7,11}$ The review of epidemiology of OCD revealed a widely divergent estimate of its incidence in adult psychiatric patients ranging from 0.1 to $4 \%$ of inpatients and $0.6 \%$ to $2 \%$ of outpatients. ${ }^{12}$ The only epidemiological study from India found lifetime prevalence of $0.6 \%$, which is considerably lower compared to the $2-3 \%$ rate reported in the European and North American studies. ${ }^{13}$

\section{Age of Onset}

About one third to one half of adult cases with OCD have their onsets in childhood and adolescence. Males have significant earlier age of onset than females. ${ }^{14}$ By the age of 25 years, over half of the patients exhibited symptoms of OCD and nearly $3 / 4$ by 30 yrs. ${ }^{10}$ Females have late mean age of onset were likely to be married and had past history of eating disorder or depression. ${ }^{15}$ Earlier age of onset of OCD was also characterized, positive family history of OCD, presence of tic disorder, sexual obsessions, hoarding repeating rituals, and need to touch compulsions. 16

\section{Gender}

While some researchers reported the female predominance, others found no evidence of a sex difference. ${ }^{17}$ Males and females were almost equally represented among compulsive checkers while women more often had compulsive washings $66 \%$ and avoidance $26 \%$ and greater comorbidity with eating and impulse-control disorders. ${ }^{18,19}$ Male patients are more likely to be single. They have chronic illness, greater social impairment, more sexual-religious and aggressive symptoms, and greater comorbidity with tic and substance use disorders.

\section{Religion}

Religious obsessions have been reported in $6 \%$ of OCD cases. ${ }^{20}$ they also found that being brought up in strict religious background makes one suffer from religious, sexual, or aggressive obsessions.

\section{Marital Status}

Higher percentage of bachelorhood/celibacy has been reported in OCD patients. $40 \%$ for men and $39.6 \%$ for women.6,7 But, others found no significant difference of marital status in OCD patients. ${ }^{21}$ Obsessional patients in India did not show high rates of celibacy and low fertility. ${ }^{22}$ Married patients were twice as likely to remit as unmarried ones. ${ }^{23}$

\section{Social Class/Intelligence}

OCD has been reported to be prevalent among people from middle and upper classes. 6,10

\section{Precipitating Factors}

Sexual marital problems were the most common precipitants. Significant events happened in $56 \%-69 \%$ cases within six months to one year before onset.6,8 In India, contact with death or illness made up bulk of reactive factors. ${ }^{24}$

\section{Genetics/Other Clinical Characteristics}

A study reported $87 \%$ concordance in monozygotic twins compared to $47 \%$ in dizygotic twins. ${ }^{25} 35 \%$ of first-degree relatives of children suffering from OCD had similar illness. ${ }^{26}$

\section{Course and Prognosis}

Studies seem to show that the prognosis of obsessional illness is worse than for other neurotic illness.5,6,11 Atypical obsessive compulsives have poor prognosis. ${ }^{27}$ One Indian study reported a favourable outcome in majority of the subjects. ${ }^{28}$ Another follow up study found that the long-term outcome of 'Predominantly obsessive' subjects did not differ from that of 'mixed' OCD. ${ }^{29}$ Patients with absent resistance and concomitant schizotypal personality disorder had high rate of treatment failure. ${ }^{30}$

\section{Insight into Obsessive-Compulsive Disorder}

Traditionally, OCD is described as a condition in which patients have good insight into their symptoms. The DSM-IV field trial demonstrated a broad range of insight with $30 \%$ having poor insight. ${ }^{31}$ It appears that patients with poor insight don't respond well to behavioural therapy.

\section{Comorbid Conditions}

Most OCD studies reported at least 50\% rate of comorbid axis I disorders and at least $40 \%$ have personality disorder. $30,32,33$ Three classes of comorbidity have been proposed namely OCD 
simplex class, OCD comorbid tic related class, and OCD comorbid affective related class. ${ }^{34}$

About $1 / 3^{\text {rd }}$ adult OCD patients also have depression and $13 \%$ for bipolar disorder. ${ }^{35,36}$ Comorbid Bipolar Disorder may herald an episodic course of OCD. $37,38,39$

OCD is distinct from other anxiety disorders in that males and females have similar lifetime prevalence rate for OCD.18,40 Lifetime prevalence rate for panic disorder in primary OCD patients is between $12 \%$ to $15 \% .^{36,41}$ OCD with comorbid GAD was associated with higher rates of indecisiveness and pathological responsibility among adults. ${ }^{42}$ Anorexia and bulimia nervosa have high incidence of comorbid OCD. ${ }^{43}$ Lifetime prevalence rate for hypochondriasis in a sample of primary OCD patients to be $23 \%{ }^{36}$

About one third to one half of patients with Tourette's disorder are afflicted with OCD. ${ }^{4}$ Also, high rate of OCD and tics were found in the first-degree relatives of children with OCD. 45 Trichotillomania usually begins during adolescence and appears to occur much more frequently in females than males. ${ }^{46}$

$10-60 \%$ of schizophrenics exhibit symptoms of OCD. 47,48 This subgroup had earlier onset of schizophrenia, lower socioeconomic status, negative symptoms, and more severe schizophrenia. ${ }^{49}$

After the introduction of DSM III, over $50 \%$ of OCD patients met criteria for at least one personality disorder. ${ }^{50}$ Most common personality disorders were obsessive compulsive personality disorder (46\%) and avoidant (31\%). ${ }^{36}$

\section{RESULTS}

\begin{tabular}{|c|c|c|}
\hline $\begin{array}{c}\text { Age group } \\
\text { (Years) }\end{array}$ & $\begin{array}{c}\text { Number } \\
\text { (N) }\end{array}$ & $\begin{array}{c}\text { Percentage } \\
\text { (\%) }\end{array}$ \\
\hline $18-25$ & 23 & $46 \%$ \\
\hline $26-34$ & 8 & $16 \%$ \\
\hline $35-43$ & 13 & $26 \%$ \\
\hline $44-51$ & 3 & $6 \%$ \\
\hline $52-58$ & 3 & $6 \%$ \\
\hline Total & $\mathbf{5 0}$ & $\mathbf{1 0 0}$ \\
\hline Range 18 - 58 years & $\begin{array}{c}\text { Mean age } \\
\text { 30.5 years }\end{array}$ \\
\hline \multicolumn{2}{|c|}{ Table 1: Age Distribution of Patients } \\
\hline
\end{tabular}

Table 1 shows the sample size in the present study, which was 50. Age of the patients ranged from 18-58 years with the mean of 30.5 years. There were $23(46 \%)$ patients between 18 to 25 years, $8(16 \%)$ between 26 to 34 years, $13(26 \%)$ between 35 to 43 years, $3(6 \%)$ each to $44-51$ and 52 to 58 years of age.

\begin{tabular}{|c|c|c|}
\hline Sex & Number (N) & Percentage (\%) \\
\hline Male & 22 & 44 \\
\hline Female & 28 & 56 \\
\hline Total & $\mathbf{5 0}$ & $\mathbf{1 0 0}$ \\
\hline \multicolumn{2}{|c|}{ Table 2: Sex Distribution of Patients } \\
\hline
\end{tabular}

Table 2 shows that among the patients 22 (44\%) were males and 28 (56\%) were females.

\begin{tabular}{|c|c|c|}
\hline Marital Status & Number (N) & Percentage (\%) \\
\hline Single & 19 & 38 \\
\hline Married & 31 & 62 \\
\hline Total & $\mathbf{5 0}$ & $\mathbf{1 0 0}$ \\
\hline \multicolumn{3}{|c|}{ Table 3: Marital Status } \\
\hline
\end{tabular}

Table 3 shows that 19 (38\%) of the patients were single and $31(62 \%)$ were married.

\begin{tabular}{|c|c|c|}
\hline Domicile & Number (N) & Percentage (\%) \\
\hline Rural & 30 & 60 \\
\hline Urban & 20 & 40 \\
\hline Total & $\mathbf{5 0}$ & $\mathbf{1 0 0}$ \\
\hline \multicolumn{3}{|c|}{ Table 4: Domicile } \\
\hline
\end{tabular}

Table 4 shows that patients from rural area were $30(60 \%)$ and from urban areas were 20 (40\%).

\begin{tabular}{|c|c|c|}
\hline Education & Number (N) & Percentage (\%) \\
\hline Illiterate & 10 & 20 \\
\hline $\begin{array}{c}\text { Up to Secondary } \\
\text { Education }\end{array}$ & 42 & 54 \\
\hline Up to Graduation & 13 & 26 \\
\hline \multicolumn{2}{|c|}{ Total Table 5: Educational Status } \\
\hline \multicolumn{2}{|c|}{}
\end{tabular}

Table 5 shows that 15 of the total sample (30\%) were illiterate while 22 (44\%) had up to secondary schooling and 13 $(26 \%)$ had education up to graduation.

\begin{tabular}{|c|c|c|}
\hline Family Income & Number (N) & Percentage (\%) \\
\hline Low-Income Group & 16 & 32 \\
\hline Middle-Income Group & 31 & 62 \\
\hline High-Income Group & 3 & 6 \\
\hline \multicolumn{2}{|c|}{ Total Table 6: Family Income } \\
\hline \multicolumn{2}{|c|}{}
\end{tabular}

Table 6 shows that $16(32 \%)$ of OCD patients belong to low income group whereas family income of $31(62 \%)$ and $3(6 \%)$ patients belong to middle income and high income group.

\begin{tabular}{|c|c|c|}
\hline Religion & Number (N) & Percentage (\%) \\
\hline Hindu & 47 & 94 \\
\hline Muslim & 3 & 6 \\
\hline Total & $\mathbf{5 0}$ & 100 \\
\hline \multicolumn{3}{|c|}{ Table 7: Religion } \\
\hline
\end{tabular}

Table 7 shows that the sample consisted predominantly of Hindus. 47 (94\%) were Hindus while the rest $3(6 \%)$ were Muslims.

\begin{tabular}{|c|c|c|}
\hline Disorder & Number (N) & Percentage (\%) \\
\hline Absent & 35 & 70 \\
\hline Affective & 11 & 22 \\
\hline Schizophrenic & 2 & 4 \\
\hline OCD & 2 & 4 \\
\hline Total & $\mathbf{5 0}$ & $\mathbf{1 0 0}$ \\
\hline \multicolumn{2}{|c|}{ Table 8: Family History } \\
\hline
\end{tabular}

Table 8 shows that there was no family history of mental illness in $35(70 \%)$ of cases. $11(22 \%)$ patients had family history of affective disorder, and 2 (4\%) each of schizophrenia and OCD respectively.

\begin{tabular}{|c|c|c|}
\hline Duration of Illness & Number (N) & Percentage (\%) \\
\hline$>2$ years & 35 & 70 \\
\hline$<2$ years & 15 & 30 \\
\hline Total & $\mathbf{5 0}$ & $\mathbf{1 0 0}$ \\
\hline \multicolumn{2}{|c|}{ Table 9: Duration of Illness } \\
\hline
\end{tabular}

Table 9 shows that $15(30 \%)$ patients had duration of illness less than two years while the rest had illness of more than two years. 


\begin{tabular}{|c|c|c|}
\hline Disorder & Number (N) & Percentage (\%) \\
\hline None & 23 & 46 \\
\hline Depression & 21 & 42 \\
\hline Phobia & 4 & 8 \\
\hline Schizophrenia & 1 & 2 \\
\hline Mania & 1 & 2 \\
\hline Total & 50 & 100 \\
\hline \multicolumn{2}{|c|}{ Table 10: Comorbid Axis I Disorder } \\
\hline
\end{tabular}

Table 10 shows that depression was most common comorbid disorder. 21 cases (42\%) had depression. Phobia 4 cases (8\%), Schizophrenia 1 case $(2 \%)$, and mania 1 case $(2 \%)$ were the other comorbid disorders. There were no comorbid disorders in $23(46 \%)$ of cases.

\section{DISCUSSION}

The present study had a sample of 50 compared favourably with that of other authors. ${ }^{27,30}$ In the present study, ICD-10 criteria was used for the diagnosis of OCD and Y-BOCS checklist for study of phenomena of OCD. For comorbidity study, M.I.N.I 5.0 was used in present study. Previous studies have used ICD-9 and DSM III for diagnosis. ${ }^{22,51}$ Some studies used semi-structured personal interviews to arrive at the diagnosis. In these studies, obsessive compulsive and associated phenomena were collected from the patients' case records using a checklist.

Age Distribution: As seen in Table 1, 46\% of patients were between $18-25$ yrs. of age and 16\% were between 26-34 yrs. of age. This was comparable to the finding from other studies where over half of the patients exhibited symptoms of OCD. $35-43$ yrs. (26\%), 44-51 (6\%), and 52-58 yrs. (6\%) made up the remaining patients.

Sex Distribution: The sex distribution of 50 patients included in the study was $44 \%$ males and $56 \%$ females as seen in Table 2. There was a slight female preponderance. The female predominance in OCD has been reported by various authors. ${ }^{52}$ One Indian study reported a lower rate of psychiatric help seeking among females in the developing country. ${ }^{51}$ But, the current study shows a higher rate of females seeking treatment than males.

\section{Marital Status}

Celibacy rate of $40-50 \%$ for men and $27-39 \%$ for women have been reported in OCD patients. 7 , In the present study, 19 (38\%) subjects were single and $31(62 \%)$ were married as seen in Table 3. 16 males and 3 females were single. Nearly all males were between 20-25 years of age and were students i.e. not having been considered for marriage by their families. Therefore, this could not be considered in celibacy rate. However, one previous study has mentioned various sociocultural factors operating in this area, which lead to low celibacy rate in India as compared to western studies. One of such factor is strong pressure against bachelorhood in Indian families. ${ }^{22}$

\section{Domicile}

$40 \%$ of cases were from urban background and $60 \%$ were rural as seen in Table 4 . The overall representation of rural patients in this study from the state like Andhra Pradesh seems to be a consequence of the fact that most of the psychiatric services in India are now reaching in rural areas and in areas in and around Vijayawada.

\section{Education}

Several studies suggest that obsessive compulsive patients are of above average social class and intelligence. ${ }^{10}$ In the present study, $20 \%$ were illiterates, $54 \%$ had up to secondary schooling, and only had $26 \%$ up to graduate as seen in Table 5 . This possibly suggests a changing trend that even people with low education status are aware about OCD and are willing to take treatment.

\section{Family Income}

People from middle and upper classes were affected with OCD more commonly. ${ }^{6}$ But, in the present study, $32 \%$ patients were from low-income group, $62 \%$ were from middle-income group, and $6 \%$ were from upper-income group as seen in Table 6 . The factors contributing again would be the awareness about psychiatric illness and affordability of medication and treatment.

\section{Religion}

The present study found $94 \%$ of the patients were Hindus and $6 \%$ consisted of Muslims as seen in Table 7. This may reflect the role of socio-cultural factor in OCD. The Indian population dominated by Hindus with the cultural emphasis on the value of cleanliness of the body as well as surroundings maybe an influencing factor. The Hindu code or ethnic provides a great variety of purification rituals. The scripture regards the human body as basically dirty and an object of disgust and need for repeated cleansing of one's body is over emphasized.

\section{Family History}

In the present study, it was found that $4 \%$ of the patients had family history of OCD, $22 \%$ had family history of affective disorder, and $4 \%$ had family history of schizophrenia. $70 \%$ had no family history of mental illness as seen in Table 8. In a study, $35 \%$ of first-degree relatives of OCD patients suffering from OCD. ${ }^{26}$ In another study, 35.5\% relatives of OCD children had clinical or subclinical OCD. The lower percentage of family history of OCD in the present sample maybe due to difficulty identifying subclinical syndrome from culturally sanctioned behaviours.

\section{Duration of Illness}

$70 \%$ of the patients had OCD of more than two years and rest had duration of illness less than 2 years as seen in Table 9. The present study was based on one-time contact with the patients; therefore, the course of illness could not be compared with other studies.

\section{Comorbid Axis I Disorders}

The present study revealed presence of depression in $42 \%$ of the patients, phobia in $8 \%$ of cases, schizophrenia and mania in $2 \%$ cases each as seen in Table 10 . The relationship between obsessions and depression has also been noted in previous studies. ${ }^{5}$ Very high rate of depression (42\%) was also found in the index study as in another study in $45 \%$ of patients.

A study described schizophrenia in $12 \%$ of OCD patients while another found $3.5 \%$ obsessional symptoms in schizophrenics. 47

The current study also found that $2 \%$ of patients satisfied criteria for schizophrenia. However, as found in other studies, only one patient had OCD symptoms with mania. 


\section{SUMMARY AND CONCLUSIONS}

50 consecutive patients, both male and female took part in this study and they had satisfied the ICD-10 diagnostic guidelines for OCD. They were interviewed for socio-demographic data and the Y-BOCS checklist and M.I.N.I were administered. The data were observed and following conclusions were drawn.

1. Variables Sex, Gender, Education, and Socio-Economic Class have shown a gradual change like in: More female preponderance, higher awareness of the illness among the middle and lower economic class along with illiterates and undergraduates of people over the years. Most patients were between the age group of 18-25 yrs.

2. Rural and low and middle income patients are increasingly seeking treatment for OCD.

3. Most common family history of psychiatric illness found was affective disorders.

4. Most patients had a duration of illness of more than $2 \mathrm{yrs}$.

5. Depression as a syndrome was found to be the common comorbidity in OCD whose trend has remained the same over the years.

\section{REFERENCES}

1. Reddy JYC, Rao NP, Sumant K. An overview of Indian research in obsessive-compulsive disorder. Indian Journal of Psychiatry 2010;52(Suppl 1):200-9.

2. WHO. International Classification of Disease-10, (ICD10). Mental and behavioural disorders. Geneva: WHO, 1992.

3. Goodman WK, Price LH, Rasmussen SA, et al. The YaleBrown obsessive-compulsive scale. I. development, use, and reliability. Archives of General Psychiatry 1989;46(11):1006-11.

4. Sheehan DV, Lecrubier Y, Sheehan KH, et al. The Mini International Neuropsychiatric Interview (MINI): the development and validation of a structured diagnostic psychiatric interview for DSM-IV and ICD-10. Journal of Clinical Psychiatry 1998;59(20):22-33.

5. Lewis AJ. Problem of obsessional illness. Proceedings of Royal Society of Medicines 1936;29(4):325-36.

6. Ingram IM. Obsessional illness in hospital patients. Journal of Mental Science 1961;107:382-402.

7. Kringlen E. Obsessional neurotics-a long-term follow up. British Journal of Psychiatry 1965;111(477):709-22.

8. Lo WH. A follow up study of obsessional neurotics in Hong Kong, Chinese. British Journal of Psychiatry 1967;113(501):823-32.

9. Templer DI. The obsessive-compulsive neurosis: review of research findings. Comprehensive Psychiatry 1972;13(4):375-83.

10. Black A. The natural history of obsession neurosis. In Beech Hr (ed). Obsessional states London. Methuer and Co 1974.

11. Pollit J. Natural history of obsessional states. British Medical Journal 1957;1(5012):194-8.

12. Rasmussen SA, Tsuang MT. Epidemiology of OCD. Journal of Clinical Psychiatry 1984;45:450-7.

13. Khanna S, Gururaj G, Sriram TG. Epidemiology of obsessive-compulsive disorder in India presented at the first international obsessive-compulsive disorder congress. Capri 1993:9-12.
14. Hollingsworth C, Tanguay P, Grossman L, et al. Long-term outcome of obsessive-compulsive disorder in childhood. Journal of the American Academy of Child and Adolescent Psychiatry 1980;19(1):134-44.

15. Castle DJ, Dale A, Marks IM. Gender difference in OCD. Australian-New Zealand Journal of Psychiatry 1995;29(1):114-7.

16. Narayanaswamy JC, Viswanath B, Cherian VA, et al. Impact of age of onset of illness on clinical phenotype in OCD. Psychiatry Research 2012;200(2-3):554-9.

17. Rasmussen SA, Eisen JL. The epidemiology and differential diagnosis of OCD. Journal of Clinical Psychiatry 1992;53:4-10.

18. Noshirvani NF, Kasvikis Y, Marks IM, et al. Gender divergent aetiological factors in obsessive-compulsive disorder. British Journal of Psychiatry 1991;158(2): 260-3.

19. Torres AR, Moran P, Bebbington P, et al. Obsessivecompulsive disorder and personality disorder: evidence from the British National Survey of Psychiatric Morbidity 2000. Social Psychiatry and Psychiatric Epidemiology 2006;41(11):862-7.

20. Coryell W. Obsessive-compulsive disorder and primary unipolar depression: comparison of background family history, course and mortality. Journal of Nervous and Mental Diseases 1981;169(4):220-4.

21. Akhtar S, Wig NN, Varma VK, et al. A phenomenological analysis of symptoms obsessive-compulsive neurosis. British Journal of Psychiatry 1975;127(4):342-8.

22. Steketee G, Eisen JL, Dyke I, et al. Predictors of course in obsessive-compulsive disorder. Psychiatric Research 1999;89(3):229-38.

23. Khanna S, Rajendra PN, Channabasavanna SM. Phenomenology of obsessions in obsessive-compulsive neurosis. Psychopathology 1988;21(1):12-8.

24. Carey G, Gottesman II. Twin and family studies of anxiety, phobic, and obsessive disorder. In: Klein DF, Rabkin J (eds). Anxiety-New research and changing concepts. New York Raven Press 1981:117-36.

25. Lenane MC, Swedo SE, Leonard $\mathrm{H}$, et al. Psychiatric disorders in first-degree relatives of children and adolescents with OCD. Journal of the American Academy of Child and Adolescent Psychiatry 1990;29(3):407-12.

26. Solyom L, Dinicola VF, Sookman D, et al. Is there an obsessive psychosis? aetiological and prognostic factors of an atypical form of obsessive-compulsive neurosis. Canadian Journal of Psychiatry 1985;30(5):327-379.

27. Reddy YC, D'Souza SM, Shetti C, et al. An 11-to 13-year follow-up of 75 subjects with obsessive-compulsive disorder. Journal of Clinical Psychiatry 2005;66(6):744-9.

28. Math SB, Thoduguli J, Reddy JYC, et al. A 5-year course of predominantly obsessive vs. mixed subtypes of obsessive-compulsive disorder. Indian Journal of Psychiatry 2007;49(4):250-5.

29. Jenike MA, Baer L, Minichiello WE, et al. Concomitant obsessive-compulsive disorder and schizotypal personality disorder. American Journal of Psychiatry 1986;143(4):530-3.

30. Foa EB, Kozak MJ, Goodman WK, et al. DSM-IV field trial: obsessive-compulsive disorder. American Journal of Psychiatry 1995;152(1):90-6. 
31. Hollander E. Obsessive-compulsive related disorders. Washington DC, American Psychiatry-Press 1993:286.

32. Nestadt G, Di CZ, Riddle MA, et al. Obsessive-compulsive disorder: sub-classification based on comorbidity. Psychological Medicine 2009;39(9):1491-501.

33. Weismann MM, Bland RC, Canino GJ, et al. The cross national epidemiology of obsessive compulsive disorder the cross national collaborative group. Journal of Clinical Psychiatry 1994;55:5-10.

34. Pigott TA, L'Heureux F, Dubbert B, et al. Obsessive compulsive disorder: comorbid conditions. Journal of Clinical Psychiatry 1994;55:28-32.

35. Hantouche EG, Angst J, Demonfaucon C, et al. Cyclothymic OCD: a distinct form? Journal of Affective Disorders 2003;75(1):1-10.

36. Millet B, Kochman F, Gallarda T, et al. Phenomenological and comorbid features associated in comorbid obsessivecompulsive disorder: influence of age of onset. Journal of Affective Disorders 2004;79(1-3):241-6.

37. Maina G, Albert U, Pessina E, et al. Bipolar obsessivecompulsive disorder and personality disorders. Bipolar Disorder 2007;9(7):722-9.

38. Karno M, Golding JM, Sorenson SB, et al. The epidemiology of obsessive-compulsive disorder is five US communities. Archives of General Psychiatry 1988;45(12):1094-9.

39. Katon W. Panic disorder and somatization. American Journal of Medicine 1984;77(1):101-6.

40. Abramowitz JS, Foa EB. Worries and obsessions in individuals with obsessive-compulsive disorder with and without comorbid generalized anxiety disorder. Behaviour Research and Therapy 1998;36(7-8):695-700.

41. Rubenstein CS, Pigott TA, Heureux F, et al. A preliminary investigation of the lifetime - prevalence of anorexia and bulimia nervosa in patients with obsessive-compulsive disorder. Journal of Clinical Psychiatry 1992;53(9): 309-14.

42. Pitman RK, Green RC, Jenike MA, et al. Clinical comparison of Tourette's disorder and obsessivecompulsive disorder. American Journal of Psychiatry 1987;144(9):1166-71.
43. Leonard $\mathrm{H}$, Swedo S, Lenane $\mathrm{M}$, et al. A 2 to 7 years follow up study of 54 obsessive compulsive disorder children and adolescents. Archives of General Psychiatry 1993;50(6):429-39.

44. Krishnan K, Davidson J, Guajardos C. Trichotillomania: a review. Comprehensive Psychiatry 1985;26(2):123-8.

45. Rosen I. The clinical significance of obsessions in schizophrenia. Journal of Mental Sciences 1957;103: 773-85.

46. Fenton WS, McGlashan, Thomas H. Long-term outcome of obsessive-compulsive disorder with psychotic feature. Journal of Nervous and Mental Diseases 1990;178(12):760-1.

47. Owashi T, Ota A, Otsubo T, et al. Obsessive-compulsive disorder and obsessive-compulsive symptoms in Japanese in patients with chronic schizophrenia-a possible schizophrenic subtype. Psychiatry Research 2010;179(3):241-6.

48. Mavissakalian M, Hamann MS, Jones B. DSM-III personality disorders in obsessive-compulsive disorder: changes with treatment. Comprehensive Psychiatry 1990;31(5):432-7.

49. Khanna S, Kaliaperumal VG, Channabasavanna SM. Clusters of obsessive-compulsive phenomenon in obsessive-compulsive disorder. British Journal of Psychiatry 1990;156(1):51-4.

50. Hare EH, Price JS, Slater ET. Fertility in obsessional neurosis. British Journal of Psychiatry 1972;121 (561): 197-205.

51. Riddle MA, Schaill L, King R, et al. OCD in children and adolescents: phenomenology and family history. Journal of the American Academy of Child and Adolescent Psychiatry 1990;29(5):766-72.

52. Valleni-basile LA, Garrison CZ, Jackson KL, et al. Frequency of obsessive-compulsive disorder in a community sample of young adolescents. Journal of the American Academy of Child and Adolescent Psychiatry 1994;33(6):782-91. 